\title{
DEBATES E PERSPECTIVAS DO LUGAR NA GEOGRAFIA
}

\author{
FLÁVIO BARTOLY \\ Universidade Federal Fluminense
}

Impõe-se, ao mesmo tempo, a necessidade de, revisitando o lugar no mundo atual, encontrar os seus novos significados (SANTOS, 2002, p. 315)

\section{Introdução}

O status de "conceito-chave" não reflete a atenção ou a importância dispensada ao lugar no âmbito da geografia. Na verdade, se comparado aos conceitos de espaço, território, região e paisagem, o lugar foi, e de certa forma continua sendo, esquecido nos trabalhos dos geógrafos. Quando não é esquecido, acaba sendo confundido. Talvez, mais danoso do que o esquecimento seja a aplicação incorreta do conceito. É precisamente por meio de uma reflexão acerca de algumas dessas questões que pretendemos contribuir com o avanço dos debates sobre o conceito. Neste artigo, selecionamos alguns temas de discussão referentes à validade da conceituação e aplicação do lugar na geografia.

Em um mundo que se encontra dominado, em grande medida, pelo estágio avançado da chamada "globalização", em que "todos os lugares ficam vulneráveis à influência direta do mundo mais amplo" (Harvey, 2003 , p. 221), o conceito de lugar se apresenta com um grande potencial para conseguirmos "aprender a lidar com um avassalador sentido de compressão dos nossos mundos espacial e temporal" (Idem, p. 219). Apesar disso, temos a impressão de que o lugar não vem recebendo reflexões mais atentas no campo das ciências sociais. Parece-nos que ou há uma dificuldade prévia, por parte dos cientistas sociais, em trabalhar com o conceito, ou há um quase consenso de que o lugar não traz questionamentos e esclarecimentos importantes para nos ajudar a compreender melhor a lógica do espaço geográfico. Alain Bourdin parece acreditar na "dificuldade que têm os historiadores e os geógrafos, como também os sociólogos e antropólogos, em construir um 'paradigma do local'" (Bourdin, 2001, p. 25). Edward Relph é mais enfático e específico quando demonstra espanto não só com o desinteresse dos arquitetos, mas, principalmente, com o fracasso dos geógrafos em explorar o conceito de 
lugar. Este fracasso estaria relacionado com o fato de que os geógrafos muitas vezes acreditam que, sendo o lugar um conceito considerado importante para a geografia, necessariamente deva possuir uma história de discussões bem estabelecidas e elucidadas (Relph, 1976).

As amplas e difundidas discussões acerca dos conceitos de espaço, território e região deixam aqueles que se ocupam especificamente do conceito de lugar com a clara noção de que há muito trabalho pela frente. Até mesmo o conceito de paisagem possui reflexões e sistematizações mais consistentes do que o conceito de lugar (Haesbaert, 2002). "O lugar nunca se destacou como conceito da geografia, sendo quase sempre tomado como referência locacional" (Holzer, 2000, p.113).

Algumas reflexões se impõem sobre a noção de lugar e sobre a pertinência de considerá-la na pesquisa geográfica. É uma noção da qual estamos longe de haver tirado partido para compreender o contexto atual da modernidade (ou pósmodernidade, segundo o ponto de vista) [...] É tanto mais interessante que poucos geógrafos se interessaram pela noção de lugar num contexto de modernidade e de exercício da democracia (Berdoulay, 1999, p. 88).

Desse modo, conscientes das potencialidades do conceito, bem como da necessidade de afinarmos constantemente os instrumentos conceituais da geografia e do desafio de pensar sociedades e espaços (lugares) em ininterrupta produção, nos lançamos à tarefa de pontuar aquilo que consideramos como alguns aspectos que precisam ser repensados acerca do lugar e, por meio deles, desenvolver algumas ideias sobre o conceito.

\section{O local e o lugar para além da geografia humanista.}

Um primeiro aspecto a ser considerado, muito corrente por sinal no discurso geográfico, relaciona-se à falta de rigor conceitual que proporciona o tratamento do lugar como um substantivo comum, uma simples palavra, sinônimo de local. Na linguagem do senso comum isto talvez possa parecer livre de causar qualquer tipo de confusão no entendimento do que se quer apontar. Todavia, no campo das ciências sociais, é importante que lembremos as diferenças fundamentais que se podem estabelecer entre o lugar e o local. ${ }^{1} \mathrm{~A}$ ideia do local relaciona-se a

\footnotetext{
1 "Para apreender essa nova realidade do lugar, não basta adotar um tratamento localista, já que o mundo encontra-se em toda parte" (Santos, 2002, pg.314).
} 
uma noção cartográfica, ao sentido exato de apontar onde está alguém ou algo. O lugar possui uma localização no espaço, contém o local, mas vai muito além dele. Para Susanne Langer, o lugar é culturalmente definido, já o local é uma qualidade incidental do lugar, definida pela cartografia (Relph, 1976). Fred Lukermann acredita que um lugar não é só o onde de alguma coisa, mas é o local somado a tudo que está implícito como o aspecto essencial da base fenomenológica da geografia (apud Relph, 1976).

Em quaisquer das correntes de pensamento da geografia que trataram e tratam do lugar, reduzi-lo ao sinônimo de local marca um grave erro. A importância da corrente conhecida como Geografia Humanista para o estudo aprofundado do conceito de lugar é inegável. Geógrafos como YiFu Tuan, Edward Relph, Anne Buttimer, Fred Lukermann e Susane Langer conseguiram, por meio de um aporte filosófico baseado no existencialismo e na fenomenologia husserliana, trazer o lugar para o centro da discussão na geografia. Entretanto, geógrafos como David Harvey, Robert Sack, Doreen Massey, Milton Santos e, mais recentemente, Nicholas Entrikin, John Agnew, Tim Cresswell, Tim Oakes, Andrew Merrifield, entre outros, exploraram profundamente o conceito de lugar a partir de outras perspectivas.

Assim, o segundo debate que apontamos é exatamente a redução da história do pensamento acerca do lugar na geografia à corrente humanista. Ainda que tenha sido aquela que obteve mais visibilidade, a corrente crítica e as abordagens mais recentes, notadamente os trabalhos de Nicholas Entrikin, abrem perspectivas diferentes e fundamentais para avançarmos no estudo do conceito. Para a geografia crítica, a especificidade do lugar advém do papel que este representa na dinâmica capitalista. Na definição do conceito, não é necessário que o lugar desfrute de uma longevidade para que seja relevante, mas que desempenhe uma função importante que o diferencie dos demais. Com isso, um lugar se destaca e, por conseguinte, torna-se singular, a partir de sua maior ou menor capacidade técnica e de comunicação, por exemplo. À medida que o lugar apresenta uma estrutura funcional adequada, tem-se a impressão de que o mundo necessariamente passa pelo lugar, de que os fluxos globais não só atravessam-no, como estabelecem com ele uma relação dialética. Neste sentido, é exatamente essa relação dos fluxos globais com as condições locais que produz o lugar na geografia crítica. Assim, o lugar é definido a partir das relações que mantém com a totalidade, a qual seria manobrada pelo movimento histórico do capitalismo. Desse modo, a especificidade do lugar mantém, então, uma ligação indissociável com o tempo histórico, na medida em que 
o significado do lugar se modifica à medida que o capitalismo se transforma.

O lugar, aliás, define-se como funcionalização do mundo e é por ele (lugar) que o mundo é percebido empiricamente (...). Assim, cada lugar se define tanto por sua existência corpórea, quanto por sua existência relacional (Santos, 2002a, p.158 \& 159).

Nas abordagens mais recentes, os geógrafos têm refletido acerca de um lugar que seria o produto da complementação das dimensões propostas pela geografia humanista e pela geografia crítica. É justamente da tensão entre a subjetividade e a objetividade que nasce o lugar composto pela dimensão material, aquela que nos fala da localização dos objetos, de sua distribuição objetiva no espaço e da relação do lugar com a totalidade; e, pela dimensão abstrata, aquela que trata dos símbolos e dos significados que são atribuídos pelos indivíduos ao lugar e dão sentido à própria arrumação dos objetos e das pessoas nesta porção do espaço geográfico. Privilegiar apenas uma dessas dimensões nos conduzirá ou a uma perspectiva em que a importância do lugar como componente fundamental da identidade do indivíduo seja, por demais, diminuída, ou, por outro lado, a tratarmos o lugar como um fenômeno apenas abstrato, desprovido de materialidade. Pois "mesmo quando começa a viver humanamente, a casa não perde toda a sua objetividade" (Bachelard, 1989, p. 64).

We live our lives in place and have a sense of being part of place, but we also view place as something separate, something external. Our neighborhood is both an area centered on ourselves and our home, as well as an area containing houses, streets and people that we may view from a decentered or an outsider's perspective. Thus place is both a center of meaning and the external context of our actions (Entrikin, 1991, p. 7, grifos nossos)

$\mathrm{Na}$ verdade, Entrikin defende uma ideia de lugar que é tributária de uma mediação entre as perspectivas dos geógrafos críticos - muito atentas às relações mantidas entre a circulação do capital, a influência das técnicas e das estruturas socioespaciais e o lugar - e a perspectiva dos "humanistas" - com seus significados e valores atribuídos ao espaço, que então se torna lugar. As análises que trabalham somente com os aspectos subjetivos do 
lugar são classificadas pelo autor como uma perspectiva "centrada", em oposição a uma abordagem "descentrada", relacionada às análises que enfocam o lugar a partir de uma perspectiva mais objetiva.

...by involving the notion of an 'in between' it seeks to understand how two polar opposites can be brought together rather than to comprehend how the locus of place is a unity containing within itself different aspects. The dialectical standpoint opposes the reification (Merrifield, 1993, p. 519).

\section{O "núcleo do conceito", as interfaces e a(s) escala(s) do lugar}

A partir do momento em que o lugar passa a ser objeto de reflexão conceitual, parece haver um consenso de que estamos falando necessariamente de uma pequena porção do espaço. Assim, podemos admitir que há uma tentação em definir ou a iniciar uma construção conceitual do lugar através de suas dimensões. Partimos então da ideia de um espaço necessariamente "menor", restrito a alguns indivíduos, composto por algumas poucas paisagens. Essa questão torna-se ainda mais complexa, quando acrescentamos o fato de que a chamada globalização ampliou por demais a tensão entre "o global e o local", sendo este último comumente tomado como sinônimo de lugar. À medida que as transformações socioeconômicas e as articulações espaciais passaram a correntemente estabelecer uma fluidez cada vez maior em suas relações, essa questão passou a ter uma enorme importância no debate relativo ao conceito de lugar.

This tension between global integration and territorial
redifferentiation leads to a 'generalized explosion of spaces'
in which the relations among all geographical scales are
continuously rearranged and reterritorialized (Lefebvre,
1979 , apud Brenner, 2000, p.361).

Partimos da ideia de que a análise geográfica pressupõe uma escala e que promove uma compreensão diferenciada do fenômeno em questão (Castro, 1992). Não pretendemos entrar no longo e importante debate que envolve as enormes diferenças entre as escalas cartográfica e geográfica, e que objetiva desfazer certa confusão entre as duas categorias. Nossa confusão é outra. Consideramos, na discussão acerca do lugar, a escala geográfica como um aspecto fundamental no entendimento e nas possibilidades de aplicação do conceito. 
Entendemos a escala como uma forma de aproximação do real e que, como tal, não envolve somente o aspecto dimensional, mas principalmente um aspecto fenomenal. Ao definirmos o conceito, ou melhor, ao aprisionarmos as reflexões em uma escala, condenamos o lugar a uma posição menor diante dos outros conceitos fundamentais da geografia, não por supostamente tratar da "escala local", pois "não há escala mais ou menos válida; não há hierarquização de grandezas escalares" (Castro, 1992, p. 22), mas por não permitir o pleno desenvolvimento de reflexões que considerem múltiplas escalas. Assim, a impressão de que estamos diante de uma simples troca de termos enquanto tratamos local como lugar e vice versa nos conduz, em geografia, a um efetivo problema epistemológico. Ao partirmos do pressuposto de que o conceito de lugar se define e/ou trata, necessariamente, de fenômenos em "pequena" escala, restringimos suas possibilidades de reflexão e aplicação. Ao mesmo tempo, também estamos considerando que a subjetividade e a capacidade de envolvimento do indivíduo com determinada porção do espaço possui uma variação mínima em termos de amplitude, como se conseguíssemos medir a intensidade escalar desses sentimentos, como se todos apreendessem e conhecessem seu "espaço vivido" da mesma forma, como se a identidade e o sentido do lugar não fossem parte de uma relação mutável, estabelecida especialmente pela intencionalidade do indivíduo. Nesse contexto, lugar pode se referir à localidade, à região, ao Estado-nação, a uma entidade como a "União Europeia" ou a qualquer outra entidade geográfica (Massey, 2004, p. 20).

$\mathrm{O}$ desconhecido é um desafio. Mover-se em um espaço em que não reconhecemos as formas, em que podemos até compreender o sentido de sua arrumação, mas no qual não conseguimos imprimir as referências que nos permitam identificá-lo, causa em geral uma sensação de desconforto. Quando se constrói conhecimento sobre grandes áreas, estas podem deixar de ser um espaço indiferenciado para ser um lugar. Por meio da experiência ${ }^{2}$ no espaço, do reconhecimento de referenciais de localização e da própria vivência com outras pessoas, constrói-se um espaço familiar quanto à locomoção e também em termos de lembranças e significados, independentemente da amplidão da área. Entretanto, não podemos perder de vista o fato de que, ao mudarmos de escala, não estamos simplesmente aumentando ou diminuindo o foco de nossa lente de observação, mas transformando qualitativamente a dimensão de análise do fenômeno. Desse

\footnotetext{
2 "Experienciar é aprender; significa atuar sobre o dado e criar a partir dele (...). A experiência é constituída de sentimento e pensamento" (TUAN, 1983, p.10-11).
} 
modo, não é possível transferirmos situações de uma escala geográfica para outra impunemente, como um simples rebatimento.

Por outro lado, a sensação de pertencimento a uma porção do espaço pode estar relacionada à minha rua, ao meu bairro, ao meu estado ou ao meu país. Quando estou em meu bairro, minha identificação espacial é a minha rua. Ao caminhar pela metrópole, e ver o nome de meu bairro em uma placa, rapidamente reconheço aquele nome como parte de mim. Quando viajo pelo país, minha identificação advém, primeiramente, de meu estado. Finalmente, quando estou voltando de outro país, tenho a nítida sensação de uma volta para casa (para o meu país, para o meu lugar). Em cada uma dessas escalas geográficas temos a "produção de um lugar" qualitativamente e geometricamente distinto dos demais, que promove implicações diferenciadas em cada escala, mas que conserva o "núcleo do conceito" em todas elas.

They can be at almost any scale, depending on the manner in which our intentions are directed and focused, as a nationalist my place is the nation, but in other situations my place is the province or region in which I live, or the city or the street or the house that is my home (Relph, 1976, p.43).

Os exemplos do parágrafo anterior, que contemplam predominantemente o ambiente urbano da metrópole (globalizada), partindo do pressuposto de que estamos tratando de um indivíduo que estabelece um sentido de pertencimento em diversas escalas, podem ser úteis como uma provocação para que não deixemos de lado a grande discussão existente acerca da escala geográfica e de sua importância para o conceito de lugar. "So, rather than leading the end of geography, globalization involves the re-scaling of places" (Hudson, 1998, p. 934).

Todavia, independentemente da amplitude da área a que se faz referência, "quando o espaço nos é inteiramente familiar, torna-se lugar" (Tuan, 1983, p.83).

...those aspects of the lived-world that we distinguish as places are differentiated because they involve a concentration of our intentions, our attitudes, purposes and experience. Because of this focusing they are set apart from the surrounding space while remaining a part of it (Relph, 1976, p.43). 
Deste modo, o "tamanho do lugar" é uma dimensão relativa, que depende da escala geográfica ${ }^{3}$ em que nos situamos em uma dada situação específica. Cada indivíduo tem a capacidade de estruturar uma determinada porção do espaço, com seus referenciais, sua vivência, e torná-lo parte integrante de sua experiência.

Porque ele não implica a priori nenhuma escala, nem nenhum
enclausuramento em limites espaciais, mas por sua
materialidade, o lugar permite aproximar de um mesmo olhar
os fenômenos que estas duas concepções têm tendência a
deixar separadas (...). É no lugar que a relação com a
alteridade, posta em prática pelo outro, pode se converter em
matéria para reflexão, em reconhecimento da diferença e em
esforço de colocação em coerência (Berdoulay, 1999, p. 90).

O que estamos chamando de "núcleo do conceito" tenta expressar o fato de que existem sobreposições entre os conceitos. Entretanto, é fundamental que não nos esqueçamos dos aspectos que em última instância diferenciam e individualizam o conceito. O lugar é produzido a partir da afetividade, da sensação de pertencimento, do modo como nos adaptamos e nos apropriamos das realidades globais que se introduzem no local, que dão sentido à própria distribuição objetiva das coisas e das pessoas nessa porção do espaço geográfico. "Nessa perspectiva, nossas investigações mereceriam o nome de topofilia. Visam determinar o valor humano dos espaços de posse, dos espaços defendidos contra forças adversas, dos espaços amados" (Bachelard, 1989, p. 19). Desse modo, em um mesmo local podem ser construídos diversos lugares, já que as dimensões da subjetividade e dos significados atribuídos, que vão prover uma lógica própria para a organização e vivência desse local, são distintas entre os indivíduos. Essa necessidade de explicitarmos o que chamamos de "núcleo do conceito" é vista por Milton Santos como uma questão fundamental em sua discussão acerca das interfaces entre os conceitos de lugar e região.

A distinção entre lugar e região passa a ser menos relevante do que antes, quando se trabalhava com uma concepção hierárquica e geométrica do espaço geográfico. Por isso, a região pode ser considerada como um lugar, desde que a regra da unidade e da contiguidade do acontecer histórico se verifique. E os lugares - veja-se o exemplo das cidades

\footnotetext{
3 “....a escala cartográfica exprime a representação do espaço como forma geométrica, enquanto a escala geográfica exprime a representação das relações que as sociedades mantêm com esta forma geométrica" (Castro, 1995, p. 125).
} 
grandes - também podem ser regiões. Tanto a região, quanto o lugar, são subespaços subordinados às mesmas leis gerais de evolução. (Santos, 2002a, p. 159, grifo nosso)

Talvez seja justamente quando tratamos da extrema mobilidade ${ }^{4}$ possibilitada pela técnica nas últimas décadas, que ampliou a urgência em se observar a influência decisiva e cotidiana do global no local, que o "núcleo do conceito" e a sua escala tornam-se instrumentos fundamentais para a compreensão dessas novas realidades. "A cada temporalização prática, corresponde uma espacialização prática, que desrespeita as solidariedades e os limites anteriores e cria novos" (Santos, 2002a, p. 159).

Atualmente a ampliação de nossa mobilidade não precisa depender da experiência pessoal. Vejamos um caso específico: por meio da técnica podemos nos localizar em um espaço "desconhecido", utilizando modernos aparelhos que nos permitirão cruzar grandes distâncias sem maiores problemas. Todavia, o fato de estarmos referenciados em termos locacionais não nos permite dizer que construímos os caminhos que nos levam ao lugar. O espaço nos é familiar do modo mais distante possível, pois através da máquina procuramos evitar ao máximo a vivência do espaço, a qual constitui um elemento fundamental para produção de referências simbólicas na construção do lugar. É evidente que os aparelhos podem ajudar na localização e nos privar mais rapidamente do desconforto e da ansiedade que a sensação de "estar perdido" pode nos trazer. Mas, a partir do momento em que os instrumentos de localização passam a substituir, ou mesmo a achatar, a importância e os significados construídos através da experiência pessoal, eles nos afastam do lugar à medida que nos aproximam do local. Todavia, a conclusão de que, neste caso, a tecnologia e a consequente ampliação da mobilidade estejam "matando" o lugar seria, no mínimo, precipitada.

Aliás, a questão da mobilidade do mundo atual, típica de um espaço produzido por efeitos da "globalização", da "modernidade" ou mesmo da "pós-modernidade", é um ponto importante e trágico para a geografia

\footnotetext{
${ }^{4}$ A conhecida falta de acesso por grandes massas de indivíduos espalhados pelo mundo às principais ferramentas daquilo que chama de "meio-técnico científico e informacional" é uma das principais razões para que Milton Santos considere a chamada "aldeia global" uma das principais "fábulas" da globalização. Não se pode esquecer de que se constrói uma verdadeira geometria do poder, em relação não só às possibilidades de inclusão, como o de controle destes fluxos. Neste sentido, é urgente lembrarmos que "a compressão de tempo-espaço precisa de diferenciação social” (Massey, 2002, p. 179).
} 
humanista. A proliferação de espaços pasteurizados, assentados sobre "valores artificiais", como o consumo, e a própria constância e rapidez com que as pessoas se deslocam promoveriam uma drástica diminuição na intensidade de uma relação "autêntica" com o lugar. Nesse sentido, a contemporaneidade nos apresentaria um planeta no qual o enraizamento é cada vez menor e que, por conseguinte, ameaça a produção do lugar humanista. Por ironia, quando estamos viajando, por exemplo, a agradável sensação de familiaridade pode inesperadamente aparecer quando nos deparamos com um desses espaços pasteurizados, que são adjetivados desta forma justamente por se apresentarem de modo semelhante em uma série de pontos diferentes do "mundo globalizado". No entanto, para geógrafos humanistas como Relph, esta familiaridade é "inautêntica", artificial, não serve como base para a construção do lugar, pois foi estimulada por valores e identidades "superficiais".

Apesar de encontrarem-se dispersas pelo planeta, os mais diversos equipamentos urbanos se inscrevem em diferentes contextos, convivendo com instrumentos "locais", gostos e culturas particulares, e até com a própria diferenciação do poder de compra. Assim, o que à primeira vista poderia parecer completamente indiferenciado torna-se extremamente flexível para se inserir satisfatoriamente no contexto local. Resgata-se aí a ideia de que, neste caso, o lugar é produzido exatamente a partir da particularidade da adequação daquilo que é global àquilo que é local.

\section{Perspectivas do lugar para a análise do mundo contemporâneo e os entraves do não lugar}

Apesar de receber numerosos comentários e apontamentos em trabalhos de diversas áreas das ciências sociais, notadamente na sociologia, na antropologia e na geografia, são poucos os trabalhos que se detém a uma análise um pouco mais pormenorizada sobre a ideia do não lugar. Essa constatação pode dar a impressão de ser paradoxal, já que diante de um mundo em pleno e avançado processo de globalização, a ideia daquilo que se vem apontando como não lugar parece resolver muitos problemas e inquietações. Da mesma forma, por ser o lugar considerado um conceito basilar na geografia, o que se poderia esperar dos geógrafos seria um movimento rápido e contundente no sentido de esclarecer a ideia do não lugar, estabelecendo um debate amplo sobre seus alcances e limites.

Como dissemos anteriormente, diversos autores promovem uma tentativa de renovação da perspectiva do lugar na geografia. Todavia, essas 
tentativas parecem ainda não ter sensibilizado efetivamente a geografia brasileira. Os debates que incluem o não lugar como um desafio conceitual e metodológico para as ciências sociais e, neste conjunto, mais especialmente para a geografia, ainda são escassos. O único autor da geografia que promoveu uma reflexão mais atenta sobre o não lugar foi Edward Relph, ${ }^{5}$ há aproximadamente 30 anos (1976). Passados 20 anos, recentemente, em 1996, o antropólogo Marc Augé ${ }^{6}$ apresentou um trabalho voltado especificamente para o tema em questão. A definição do conceito de lugar para Augé está bem próxima daquela estabelecida pela chamada "geografia humanista", na qual a obra de Relph está incluída. Desse modo, ainda que encontremos marcantes divergências entre os dois autores, suas perspectivas se aproximam consideravelmente no que se refere às definições e aos exemplos de lugares e não lugares. Ou essas duas obras encerraram completamente a questão ou constata-se certo descompasso entre o uso corrente (indiscriminado) da ideia do não lugar e a pequena discussão teórica produzida a respeito, já que essas duas obras formam a "base" das formulações sobre o não lugar nas ciências sociais. Assim, distante da pretensão de desfazer esta impressão de ausência quanto às reflexões sobre o não lugar descrita na sequência acima, objetivamos resgatar certas ideias e, quem sabe, contribuir para esclarecer algumas noções que fazem parte desse conceito pouco discutido e ao mesmo tempo tão utilizado.

O não lugar é caracterizado por locais que apresentam arquitetura estandardizada, nos quais os modismos, o consumismo e o pragmatismo, valores cada vez mais difundidos e aceitos na contemporaneidade, desvirtuam valores "genuínos", como afetividade, memórias, vivência. Neste sentido, pode-se considerar o não lugar como uma experiência que, segundo alguns autores, torna-se cada vez mais comum nos dias atuais. Aquilo que Henri Lefébvre chama de "Espaço Abstrato" parece guardar uma grande proximidade com a conceituação do não lugar:

...the homogenizing efforts of the state, of political power, of the world market, and of the commodity world - tendencies which find their practical expression through and in abstract space (...). Abstract space works in a highly complex way (Lefébvre, 1991, p. 64-56).

Pode-se considerar a ideia do não lugar como tributária das concepções que tratam o lugar como um ponto de refúgio, de segurança,

\footnotetext{
${ }^{5}$ Em Place and Placelessness.

${ }^{6}$ Em Não Lugares: introdução a uma antropologia da supermodernidade.
} 
diante da avalanche de incertezas e efemeridades características do mundo atual. $\mathrm{O}$ fenômeno do não lugar é a erradicação casual de lugares significativos e a produção estandardizada de paisagens que resultam de uma insensibilidade em relação à significância do lugar. Ele resulta de um enfraquecimento da identidade dos lugares ao ponto em que fica sensível o fato de que oferecem o mesmo conjunto de possibilidades para a experiência (Relph, 1980). Relph vê o espaço existencial de uma cultura de aborígines, por exemplo, como um espaço sagrado, permeado por aspectos simbólicos. Já os espaços experimentados pelas culturas mais tecnológicas e industriais seriam funcionais, práticos, objetivos. Os "novos" espaços, produtos do desenvolvimento urbano contemporâneo, são, portanto, apontados como uniformes e cuidadosamente planejados. Esse planejamento dos espaços, que lhes dá um aspecto de uniformidade, é visto como um atentado aos possíveis significados e às afetividades que se podem manter com uma porção do espaço. "And today, as the uniqueness of places becomes more and more threatened by the homogenizing veneer of commercialism and standardized-component architecture..." (Buttimer, 1980, p.166). Além disso, o próprio sentido do lugar seria desvirtuado, tornado inautêntico, permeado por modismos e valores que afastariam o homem de sua condição de organizador de um espaço que seja uma representação genuína de seus significados e identidades. Teríamos um indivíduo aprisionado na vivência cotidiana de um espaço estereotipado, produzido em série, em que o sujeito torna-se um verdadeiro receptáculo de valores e ideias superficiais, ainda que muito eficientes para a manutenção e ampliação do sistema econômico global da contemporaneidade.

A atribuição desses adjetivos aos espaços mais "modernos" traduz uma ideia de crítica e desilusão por parte dos autores da geografia humanista. Esse discurso nos traz a impressão de que o lugar como “...espaço dotado de valor" (Tuan, 1983, p. 6) estaria aprisionado pelo passado, impossível de ser verificado e produzido no mundo atual, em meio às "perversidades" da tecnologia e da objetividade, que fazem dissipar os lugares. As experiências, singularidades e a construção de um sentido autêntico do lugar se tornariam impraticáveis em meio à parafernália tecnológica do mundo "moderno".

Relph não menciona exemplos de não lugares em sua definição, ainda que, em sua obra Place and Placelessness, redija uma lista daqueles espaços que devem, segundo ele, ser enquadrados naquele conceito. Por outro lado, Marc Augé acredita que: 
Os não lugares são tanto as instalações necessárias à circulação acelerada de pessoas e bens (vias expressas, trevos rodoviários, aeroportos) quanto os próprios meios de transporte ou os grandes centros comerciais, ou ainda os campos de trânsito prolongado onde são estacionados os refugiados do planeta (Augé, 1994, p. 36).

A reflexão de Relph girava em torno do fato de que a produção do espaço não estava mais sendo feita de modo a representar os valores históricos de determinada comunidade ou a expressar suas raízes através da constituição do bairro, da cidade, ou mesmo do país. Este processo torna-se cada vez mais claro, na medida em que até a própria casa passa a ser um produto feito em série.

Essas alterações impostas pela necessidade de prover maior eficiência e funcionalidade a determinados espaços, que por sua vez tornam-se então atrativos a investimentos maiores, promovem uma progressiva diminuição da identificação e do sentimento de pertencimento do indivíduo a um lugar que praticamente já não existe mais. Dessa forma, quanto à disposição dos objetos no espaço, impera a lógica de satisfação de interesses econômicos de escalas cada vez maiores, em detrimento dos valores produzidos pela experiência humana no espaço, seja por meio de movimentos coletivos ou de práticas individuais, os quais têm uma representatividade cada vez menor na paisagem. "The space of city planning, however, is not based on experiences of space, but is concerned primarily with function in two-dimensional map space" (Relph, 1976, p. 22).

A descaracterização da paisagem e a produção de um sentido de lugar artificial, que seriam característicos dos espaços planejados, fariam com que a diversidade de experiências em uma vizinhança do subúrbio dos EUA ou em um shopping center, por exemplo, fosse mínima. O antropólogo francês Marc Augé procede à análise do lugar e do não lugar como parte de uma reflexão sobre a contemporaneidade. Aquilo que o autor chama de "supermodernidade" resume os processos de "aceleração" da dinâmica do planeta, através dos meios de transporte e de comunicação de última geração. Augé nos fala de um período de excessos, de tempo, de espaço, em que os historiadores, economistas, antropólogos, geógrafos, ficam muitas vezes perdidos com tantas variáveis e tantas mudanças acontecendo (rapidamente), de tal modo que somos levados a repensar nossas referências de tempo e espaço. Para o autor essa é uma imposição drástica da supermodernidade. Ela nos impele a revermos nossas bases 
mais primárias, ela mexe com o íntimo de nossa reflexão e com o modo pelo qual encaramos a individualidade e a vida em sociedade.

A incrível intensidade dos fluxos de pessoas, mercadorias, informações e da própria vida de um modo geral, promove, segundo Augé, um acúmulo factual, um verdadeiro entupimento dos canais de compreensão da vida, da história e dos sentidos que atribuímos a essas referências básicas. Assim, o autor francês entende que a progressiva sensação de ausência de sentido para a vida, para a história, e o mal-estar decorrente dessas percepções nos trazem uma necessidade constante de reafirmação e/ou busca por significados e valores que diminuam nosso incômodo. Tornam-se recorrentes os momentos em que lançamos mão de ideias e conceitos que nos ajudem nessa tarefa; comunidade, identidade, enraizamento, autenticidade são palavras, conceitos e ideias que parecem confortar, que nos dão a impressão de que procedemos a uma pausa, ao reconhecimento de singelas manifestações daquilo que nos é familiar, em meio ao desconhecido que teima em prevalecer. Essa preponderância do desconhecido (da "velocidade", que é motor fundamental na produção) pode ser concebida a partir da ideia de que, quando caminhamos em direção ao fenômeno com o objetivo de reconhecê-lo, compreendê-lo e, quem sabe, dotar-lhe de significados, este já se metamorfoseou e/ou foi metamorfoseado pelo intenso ritmo da supermodernidade. A ideia de que podemos ter "acesso instantâneo ao mundo inteiro" (através dos meios de comunicação) e de que nossos atos podem ganhar uma escala jamais imaginada, traz aos ombros um peso desproporcional, que faz com que o indivíduo tente, pelo menos em alguns momentos, se afastar desse mundo que se constitui com base no desconhecido. A busca por aquilo que nos é familiar se tornaria materializada em rotas de fuga inscritas no espaço físico.

Todavia, o espaço enraizado na memória, a "terra natal", não é o espaço que prevalece na supermodernidade. Neste sentido, há outro tipo de experiência produzindo, por conseguinte, outro espaço. Para Augé, estamos falando, neste caso, do não lugar, dos espaços de circulação rápida, pasteurizados em prol da aceleração da velocidade com vistas à ampliação da realização do lucro. Nesse "novo" espaço de que fala Augé não há tempo para enraizamentos, memórias e construções que sejam a expressão de uma cultura ou de uma identidade "genuína". Com isso, a homogeneização toma conta também da produção do espaço a partir do nascimento do não lugar.

De certo modo, essa busca por aquilo que nos é familiar, pode também promover, por outro lado, o desenvolvimento de um olhar 
fantasioso sobre a realidade. "There is... no 'essential place' which exists in its real authenticity waiting to be discovered by the researcher" (Allen et al. apud Hudson, 1998, p. 934). As ideias relativas a uma sociedade tão "transparente", de produção de lugares legitimados pela cultura e pelos rituais tradicionais, de uma estabilidade que permeia um mundo fechado, intocado, produto inteiramente genuíno das origens e dos valores de um grupo social, não podem traçar a única possibilidade de aplicação do conceito de lugar. Trata-se de uma restrição que praticamente inviabiliza a capacidade explicativa do conceito, pois a existência de sociedades e/ou o estabelecimento de relações intocadas e "genuínas" com o espaço, são aspectos extremamente discutíveis e residuais. "Todas as essências tornamse eventualidades" (Massey, 2009, p. 201).

Apoiamo-nos na justificativa de Clifford Geertz para definir nosso desafio de refletir sobre o conceito de lugar por meio da importância do que está sendo transmitido pelo comportamento humano, sem a pretensão de julgar o que é genuíno, o que é autêntico, o que serve ou que não serve, até porque "não existem, de fato, homens não modificados pelos costumes de lugares particulares, nunca existiram e, o que é mais importante, não o poderiam pela própria natureza do caso" (Geertz, 1989,p. 47). A ênfase da construção da ideia de cultura para Geertz parte da premissa de que não é possível existir um único conceito de cultura que amarre e imponha limites definitivos às possibilidades de atribuição de significados pelos indivíduos.

Uma vez que o comportamento humano é visto como ação simbólica, o problema se a cultura é uma conduta padronizada ou um estado da mente, ou mesmo as duas coisas, de alguma forma perde o sentido (...). O que devemos indagar é qual é a sua importância: o que está sendo transmitido com sua ocorrência (Geertz, 1989, p. 20).

Ao entendermos o não lugar como uma experiência que tem como seu produto final a distorção dos significados mais "humanos" e "autênticos" do lugar, parece-nos que não podemos classificar como tal aqueles locais que estão distantes do nosso cotidiano, já que um bairro, um país, uma cidade ou uma localidade qualquer muito distante de nós podem ser apenas mais um ponto no mapa, uma informação abstrata com a qual não temos nenhum vínculo afetivo, psicológico ou físico. Nesse caso, estamos diante do espaço indiferenciado, de cuja identidade podemos ter uma vaga ideia e com o qual não mantemos nenhum conhecimento sobre seu "espírito", seu sentido e sua personalidade. Portanto, este é um caso em que simplesmente não há qualquer tipo de experiência em relação àqueles locais que não fazem parte de nosso cotidiano e com o qual, além disso, 
não mantemos envolvimento de qualquer espécie. Desse modo, enxergamos certa dificuldade de enquadrarmos esta questão aos contornos da discussão lugar/não lugar, já que não há uma relação, autêntica ou não, com esta determinada porção do espaço. Essa impossibilidade não está diretamente relacionada ao fato de que o local em questão não faz parte de nosso cotidiano, mas, como dissemos anteriormente, é indissociável do fato de que se trata de uma porção do espaço com a qual não temos nenhum tipo de vínculo. Se não estabelecemos nenhum vínculo, estamos falando do espaço, ${ }^{7}$ e não do lugar ou mesmo do não lugar. A estes dois últimos são atribuídos valores, significados, sentidos diferenciados pela autenticidade e pela inautenticidade com que são produzidos. Assim, nos parece que, dentro da perspectiva humanista, mais detidamente nas ideias de Edward Relph, o primeiro a teorizar sobre o não lugar na geografia, aquele local com o qual não mantemos vínculo de nenhuma espécie, mesmo que cheguemos a estar nele em algum momento, seria conceituado como espaço e não como não lugar.

Por outro lado, se mantemos algum tipo de relação com um local muito distante de nós, se ele tem algum significado para nós, se ele "nos diz alguma coisa", mesmo que não faça parte de nosso cotidiano, pode ser considerado um lugar, pois há uma relação mediada por símbolos e pelo conhecimento da visão de mundo que o local projeta, bem como da experiência que proporciona. Desse modo, "uma pessoa pode conhecer um lugar tanto de modo íntimo como conceitual" (Tuan, 1983, p. 7), já que "pontos distantes podem ser lugares (...) amados e reverenciados como emocionalmente próximos" (Mello, 1990, p. 106).

É fundamental a observação de que a possibilidade de produção do não lugar também é uma experiência, a qual não está relacionada ao fato de fazer ou não parte do cotidiano, mas ao tipo de relação por meio da qual nos envolvemos com o lugar. Nesse sentido, o não lugar não pode ser tratado como a simples antítese do que é o lugar. Aquilo que não se configura como lugar para a geografia humanista não pode ser "rebatido" diretamente e definido, portanto, como não lugar. Apesar do prefixo de negação, não nos parece que a ideia se encerre com este tipo de

7 “O espaço é aqui concebido em sua relação processual com a sociedade no curso da qual o espaço cria a sociedade e a sociedade cria o espaço, o espaço e a sociedade aparecendo como produtos gêmeos no plano social da história” (Moreira, 2006, p. 132). “ ...um conjunto indissociável de que participam, de um lado, certo arranjo de objetos geográficos, objetos naturais e objetos sociais, e, de outro, a vida que os preenche e os anima, ou seja, a sociedade em movimento" (Santos, 2007, p. 28). 
simplificação. Assim, nem sempre o que não identificamos como lugar poderá ser classificado como não lugar. Reafirmamos com isso que os locais com os quais não mantemos nenhum tipo de vínculo, os quais não necessariamente fazem parte de nosso cotidiano, como discutimos anteriormente, parecem inscrever-se mais adequadamente no conceito de espaço.

Entre outras questões, Relph e Augé divergem sobre a origem temporal dos não lugares. Segundo Relph, a produção de espaços estandardizados não é uma novidade do mundo contemporâneo. "In all societies of all times there has been some placelessness and insofar as lack of care for places provides a context and comparison it is essential for a sense of place" (Relph, 1976, p. 80). A novidade desta produção na atualidade seria a abrangência do fenômeno, ou seja, vivemos uma época de proliferação dos não lugares. A cada vez maior rapidez dos fluxos, que por sinal parece estar sendo o diferencial deste estágio avançado da globalização - além do planejamento dos espaços em prol dessa "eficiência" - tem sido o elemento fundamental para a homogeneização dos espaços.

Por outro lado, Marc Augé acredita que os não lugares são um fenômeno típico do mundo contemporâneo, resultado do que ele chama de "supermodernidade". Como já foi abordado, ese fenômeno estaria relacionado especialmente ao "encolhimento do planeta", à rapidez das trocas e ao ego do indivíduo que pretende interpretar por e para si mesmo as informações. Na verdade, discordamos de Augé, com base em Santos (2000), que reprova a noção de tempo e espaço contraídos.

É como se o mundo se houvesse tornado, para todos, ao alcance da mão. Um mercado avassalador dito global é apresentado como capaz de homogeneizar o planeta quando, na verdade, as diferenças locais são aprofundadas (Santos, 2000, p. 19).

Em vez de se extinguirem, os lugares parecem ter ganhado uma grande importância no que diz respeito à compreensão do mundo atual. Assim, Agnew \& Duncan (1989) acreditam que a emergência de uma comunicação de massa não leva necessariamente a uma cultura de massa. A argumentação baseia-se na questão da interpretação das mensagens recebidas. Dessa forma, se a recepção de mensagens é passível de interpretação, esta, por sua vez, depende diretamente da natureza da situação sociológica na qual diferentes espaços de referência operam. $\mathrm{O}$ mesmo estímulo não leva, necessariamente, à mesma resposta. 
À medida que a sociedade parece anestesiada com as novas modas, os novos aparelhos e os novos locais, criados e montados "com tudo aquilo que você precisa", a mercantilização da cidade torna-se a expressão mais palpável da compra e venda da própria vida do indivíduo através daquilo que os situacionistas chamaram de "Sociedade do Espetáculo". A repetição de fórmulas de produção de espaços funcionais, adequados às necessidades dos fluxos econômicos que circulam nas mais diversas escalas geográficas, são uma realidade. "A apologia das mercadorias sempre iguais sob etiquetas diferentes (...) a mesma coisa aparece em lugares inumeráveis..." (Adorno, 2007, p. 63,68). Devemos entender essa realidade como um convite a novas reflexões acerca do conceito de lugar, para que este possa ampliar sua capacidade explicativa neste ambiente, em que há a "generalização do mundo da mercadoria, com as transformações que esta expansão implica...” (Damiani, 2003, p. 367).

Desse modo, a subjetividade e a capacidade de atuação do indivíduo não podem ser tão minimizadas a ponto de concluirmos que não há quem consiga estabelecer uma relação afetiva com espaços "estandardizados". Nesse sentido, estabelecida a subjetividade como um fator basilar para reflexões espaciais, há uma profunda contradição em tentar, através do não lugar, estabelecer, a priori e de modo generalizado, uma definição da relação que será estabelecida por indivíduos e/ou grupos sociais com determinado espaço. A justificativa para esta definição de caráter geral e $a$ priori repousa no fato de que o espaço é "pasteurizado", "artificial", igual em toda parte, sendo impossível a sua diferenciação. Assim, nega-se também ao indivíduo e aos grupos sociais uma possível capacidade de subversão da lógica estabelecida nesses espaços "pasteurizados". "Place, in other words, always involves an appropriation and transformation of space and nature that is inseparable from the reproduction and transformation of society in time and space" (Pred, 1984, p. 279).

A possibilidade de manipular a ordem espacial estabelecida sempre existiu e deve ser levada em consideração, especialmente se concordarmos que o indivíduo é também agente na produção do espaço. Um exemplo importante pode ser observado através dos situacionistas, que propuseram um método de superação da chamada "Sociedade do Espetáculo" conceituado como "desvio". Os situacionistas defendem que o indivíduo tem o controle de seu tempo de vida tomado de si e transformado em um tempo controlado pelo consumo da mercadoria. O desvio (do tempo no tempo vivido) seria a apropriação, pelo indivíduo, de seu próprio tempo de vida. A partir daí, teríamos um indivíduo capaz de efetivamente construir situações para além do controle exercido pelo espetáculo. Na prática, os 
situacionistas propõem uma nova elaboração de tudo o que se apresenta no cotidiano, das artes ao urbano. "Le détournement se révèle ainsi d'abord comme la négation de la valeur de l'organisation antérieure de

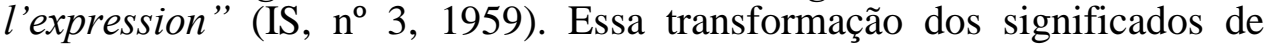
diversos elementos da vida cotidiana caracterizaria uma retomada pelo indivíduo do controle do seu tempo vivido e um rompimento com a lógica do espetáculo. "Any elements, no matter where they are taken from, can be used to make new combinations" (Debord \& Wolman, 1956).

Mesmo que os frequentadores de espaços "pasteurizados" não cheguem a subverter completamente, como propõem os situacionistas, a ordem estabelecida, é fundamental que levemos em consideração a possibilidade de apropriação desses espaços pelos indivíduos. A produção do lugar pode incluir uma forte conotação política.

A observação do grau de envolvimento que um indivíduo ou um grupo social estabelecem com o ambiente é fundamental para a ampliação da discussão, já que não podemos esquecer que os indivíduos são dotados de intencionalidade, sendo, portanto, agentes do processo de percepção do espaço. Por sua vez, a percepção não consiste, de modo algum, em um processo simplesmente contemplativo, mas de interação entre o sujeito e o objeto percebido. No caso que envolve o indivíduo e o espaço em que vive, impõe-se uma relação indissociável de influência recíproca, já que não há uma consciência separada da realidade (Merleau Ponty, 1994). Para Merleau Ponty, minha percepção do mundo não é produzida por minha observação de algo externo, mas pela certeza de que procuro entender o mundo como uma experiência da qual faço parte.

O não lugar limita profundamente as possibilidades de um indivíduo ou grupo social manter relações de afetividade e criar uma história com um espaço estandardizado, concebido a princípio para ser um local de passagem, que sirva à rapidez e à objetividade (econômica) de nosso tempo. O conceito não dá conta das mais variadas relações que os indivíduos podem estabelecer com um shopping ou um aeroporto. A dimensão do não lugar pode até existir na materialidade padronizada, montada da mesma forma em vários locais e que pode limitar a possibilidade de diferenciadas experiências sociais. Pode limitar, mas não impede que haja, através do tempo, quem veja diferenças claras entre o "seu" shopping e os outros (Bartoly, 2007). O não lugar nos chama a atenção para o aspecto cada vez mais importante da crescente produção de espaços homogeneizados (Relph, 1980). Porém o conceito aprisiona a reflexão ao estabelecer uma prévia impossibilidade do indivíduo construir 
uma história de lembranças e de afetividade que, portanto, transformem este local em lugar.

The term "placelessness", which has been used in reference to the creation of standardized landscapes that diminish the differences among places, signifies one aspect of the loss of meaning in the modern world. But "loss" may be too strong a term. Meaning is both "lost" and "gained" in such landscapes (Entrikin, 1991, pg.57).

Com isso, somos levados a refletir sobre a gama de possibilidades de relações afetivas e históricas que mesmo os "ambientes pasteurizados" podem gerar. Quem vai dizer a um funcionário de um aeroporto com mais de 30 anos de "casa" que este espaço é igual no mundo inteiro e que essa impossibilidade de diferenciação nos leva a afirmar que estamos diante de um local sem memória, com o qual não conseguimos estabelecer nenhum grau de afetividade ou de pertencimento? Para a experiência do viajante, o aeroporto talvez não consiga, realmente, despertar sua atenção ou sua afetividade, tanto pela própria característica da experiência, que é apenas de passagem, como pelo fato de ser um espaço montado a partir de planos muito parecidos e difundidos globalmente. No entanto, fica clara a diferença que não podemos deixar de considerar, quando nos remetemos à experiência do funcionário. "...O tratorista, em seu veículo, sente-se em casa na estrada; a operária sente-se em casa na fábrica de fiação; o engenheiro que dirige a central elétrica sente-se ali em casa" (Heidegger, 1979, p. 346).

Especialmente com a ampliação das funções do shopping, que deixou de ser apenas um centro de compras para também se tornar um centro de lazer, sociabilidade e serviços, esses espaços tornaram-se mais complexos. Nos primeiros tempos do shopping, a dimensão do não lugar era provavelmente mais expressiva. Todavia, especialmente por conta da sociabilidade, de modo geral, nos shoppings de hoje prevalece a dimensão "lugarizada" (Bartoly, 2007). Mesmo que tenhamos uma sociabilidade instrumental, produzida pela administração do shopping com vistas à promoção indireta de lucros, atualmente, para os frequentadores, essa instrumentalização "não aparece" e a sociabilidade torna-se um fim em si mesma. Para uma parcela importante dos milhões de assíduos frequentadores de shoppings, existem distinções muito claras entre os empreendimentos, que produzem preferências e experiências diferenciadas. Assim, nem todos conseguem "entender por que sentar num banco no shopping possa ser mais artificial do que sentar num banco no parque" (Rybczynski, 1995, p. 197). 


\section{Considerações finais}

Nesse sentido, parece-nos cada vez mais distante a validade de classificações gerais e que, a priori, procedem a simples apontamentos daqueles espaços que são ou que não são lugares. As realidades dos lugares são cada vez mais complexas e, nesse sentido, são percebidas e vividas de diferentes formas, por diferentes indivíduos. Desse modo, acreditamos que a tendência é de proliferação dos lugares, pois a possibilidade de diferentes interpretações, das inúmeras novas situações do mundo globalizado, com diferentes formatos e intensidades nas diversas localidades, nos conduz ao entendimento de que, em vez de desaparecerem, os lugares estão mudando de sentido. A ideia do não lugar parece-nos muito distante de conseguir traduzir de modo aceitável essas novas realidades.

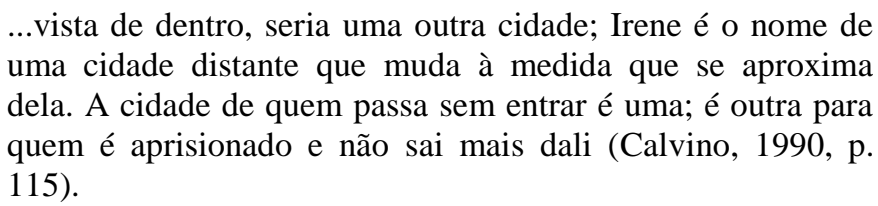

No que se refere à construção conceitual, a diferença entre o lugar, que trata quase que unicamente da dimensão subjetiva, e o não lugar repousa, efetivamente, na pretensão da autenticidade do primeiro em relação à inautenticidade do segundo. A principal semelhança trata da impossibilidade de atuação da contingência, um aspecto que se torna fundamental quando tratamos o indivíduo como sujeito da ação. Essa negação da possibilidade de transformação dos sentidos do lugar humanista e do não lugar traz como consequência primordial uma enorme dificuldade na aplicação de ambos. Ao observarmos que esses conceitos refletem predominantemente realidades definitivas, chegamos à conclusão de que não estamos diante de um complô da geografia contra o lugar, mas de uma enorme dificuldade em adequar a realidade mutável do cotidiano aos pressupostos conceituais estabelecidos.

Insistimos que ambos são implicações da construção social do espaço e que não há como estabelecermos quais espaços são mais autênticos, pois teríamos a difícil tarefa de responder para quem esses espaços seriam mais autênticos ou menos autênticos. Pressupor que a condição de local de passagem ou a previsibilidade de sua organização espacial, por conta das necessidades impostas por sua funcionalidade, excluem a possibilidade de estabelecer relações de pertencimento significa negar ao indivíduo sua indissociável condição de sujeito da produção do espaço. Certamente não estamos propondo a aceitação de quaisquer recortes como lugares ou 
mesmo negando a importância das reflexões que pavimentaram o caminho e promoveram as condições necessárias para que alguns geógrafos pudessem pretender afinar as ferramentas analíticas do lugar. Todavia, a tarefa de "tentar re-imaginar o lugar" (Massey, 2004, p. 20) e ampliar o entendimento e a aplicabilidade do conceito de lugar na geografia torna-se obrigatória e urgente. Esses avanços podem promover a superação da situação paradoxal que envolve o status de "conceito-chave" desfrutado pelo lugar na geografia e sua restrita utilização nos trabalhos dos geógrafos.

Como propõe Nicholas Entrikin, o lugar deve ser produto da tensão entre uma dimensão abstrata, afetiva, e uma dimensão material, objetiva. Doreen Massey nos lembra que há um "sentido global do lugar" (Massey, 2002) e que não podemos aprisionar o conceito em uma escala local ou a uma pretensa singularidade folclórica que traria a diferenciação necessária para conceituarmos uma determinada porção do espaço como lugar. A autora argumenta que a diferenciação do lugar advém de uma mistura singular de características locais, conjugadas com os fluxos globais que atravessam as fronteiras elásticas e porosas do lugar. Por meio de perspectivas teóricas como as lançadas por Nicholas Entrikin e Doreen Massey, a capacidade explicativa e a inserção do conceito de lugar, nos mais diversos debates das ciências sociais, ampliam-se dramaticamente.

$\mathrm{O}$ incremento da estrutura de circulação representado pela globalização nos conduz ao desafio de repensar o lugar, já que a uma maior globalidade corresponde uma maior individualidade (Santos, 2002).

\section{DEBATES E PERSPECTIVAS DO LUGAR NA GEOGRAFIA}

Resumo: O status de conceito-chave não reflete a atenção ou a importância dispensada ao lugar no âmbito da geografia. Quando não é esquecido, acaba sendo confundido. Talvez mais danoso do que o esquecimento seja a aplicação incorreta do conceito. A restrita utilização do lugar nos trabalhos dos geógrafos é a implicação mais importante da escassez de debates.

As ideias relativas a uma sociedade tão "transparente", à produção de lugares legitimados pela cultura e aos rituais tradicionais que tratam da estabilidade que permeia um mundo fechado, intocado, produto inteiramente genuíno das origens e dos valores de um grupo social não podem traçar a única possibilidade de aplicação do conceito de lugar. Trata-se de uma restrição que praticamente inviabiliza a capacidade 
explicativa do conceito, pois a existência de sociedades e/ou o estabelecimento de relações intocadas e "genuínas" com o espaço são aspectos extremamente discutíveis e residuais.

O lugar pode ser pensado como produto da tensão entre uma dimensão abstrata, afetiva, e uma dimensão material, objetiva, que não necessariamente se reduz à escala local. Assim, caminhamos para longe de reflexões que enxergam na progressiva ampliação do processo de globalização o fỉm dos lugares, ou mesmo a prevalência da produção do que chamam de "não lugares". As mais variadas transformações espaciais contemporâneas, incluindo aquelas relativas às sensações de pertencimento a uma dada porção de espaço, parecem significar um desafio, especialmente para os geógrafos, no sentido de encontrarem novos sentidos e novas perspectivas para o lugar. Distante de seu esgotamento, a produção de lugares no mundo contemporâneo, assim como ele próprio, está em permanente transformação, o que torna as reflexões mais complexas, mais instigantes e mais necessárias.

É precisamente através de uma reflexão acerca de algumas dessas questões que pretendemos contribuir com o avanço das discussões sobre o conceito. Neste artigo, selecionamos algumas questões referentes à validade da conceituação e aplicação do lugar na geografia.

Palavras-chave: lugar; conceito chave; não lugar.

\section{DEBATES AND PERSPECTIVES OF PLACE IN GEOGRAPHY}

Abstract: The status of key concept doesn't reflect the attention or the importance dispensed to place in the scope of geography. If it's not forgotten, place is misunderstood. Perhaps, more dangerous than forgetfulness, is the wrong application of the concept. The restricted use of place in the works of geographers is the most important implication of the lack of debates.

The ideas about a society so "transparent", with a production of genuine places, cultures and traditional rituals and the stability that permeates a closed world, untouched, entirely genuine product of the origins and values of a social group, cannot be the only way to apply the concept of place. It is a restriction that makes almost impossible, a development of the explanatory power of the concept, because the existence of societies, or "untouched" and "genuine" relations with space are extremely controversial and residual issues.

Place can be thought as a product of the tension between an abstract, affective dimension, and a material, objective ones, not necessarily reduced 
to the local scale. Therefore, we are faraway from the perspective which understands the progressive expansion of globalization, like a way to the end of place, or to the prevalence of the so-called "non places". The most varied contemporary spatial transformations, including those related to the feelings of belonging to a certain portion of space seem to be a challenge, especially for geographers, to find new approaches to place. Far from the end, the production of places in the contemporary world is constantly changing, which makes the analysis more complex, more exciting and more necessary.

Is precisely through a reflection about some of these questions we want to contribute with the development of the concept. In this article we select some subjects of discussion, referring to the validity of conceptualization and application of place in geography.

Key Words: place; key concept; non place.

\section{BIBLIOGRAFIA}

ADORNO, T (2007). Indústria cultural e sociedade. São Paulo: Paz e Terra.

AGNEW, J., DUNCAN, J. The Power of Place (1989). Boston: Unwin Hyman.

AUGÉ, Marc (1994). Não Lugares: introdução a uma antropologia da supermodernidade. Campinas: Papirus.

BACHELARD, Gaston (1989). A poética do espaço. São Paulo: Martins Fontes.

BARTOLY, F. S (2007). Shopping Center: entre o lugar e o não-lugar. Dissertação de Mestrado. Departamento de Geografia. UFF. Niterói.

BERDOULAY, V (1999). A ecologia urbana, o lugar e a cidadania. Revista Território, UFRJ, Rio de Janeiro. ano IV, $\mathrm{n}^{\mathbf{0}} 7$.

BOURDIN, Alain. Objeto local. In: Bourdin, Alain. A questão local. Rio de Janeiro: DP\&A, 2001. pp. 25-57.

BRENNER, N (2000). The Urban Question as a Scale Question: Reflections on Henri Lefébvre Urban Theory and Politics of Scale. International Journal of Urban and Regional Research, 24(2), pp. 361378. 
BUTTIMER, Anne (1980). Home, reach and the sense of place. In: Buttimer, A \& Seamon ,D. (eds.). The human experience of space and place. London: Croomhelm.

CALVINO, Italo (1990). As cidades invisíveis. São Paulo: Cia das Letras. CASTRO, Iná Elias de. Análise geográfica e o problema epistemológico da escala. Anu. Inst. Geocienc., vol.15, 1992, p.21-25.

(1995). O problema da escala. In: Castro, I., Corrêa. R \& Gomes, P. (orgs.) Geografia, conceitos e temas. Rio de Janeiro: Bertrand Brasil.

DAMIANI, Amélia Luisa (2003). O urbano no mundo da mercadoria. In: Carlos, A. F. \& Lemos, A. (orgs.) Dilemas Urbanos: Novas Abordagens sobre a cidade. São Paulo: Contexto.

DEBORD, G. \& WOLMAN, G (1956). A user's guide to détournement. 1956. In: KNABB, Situacionist International Anthology. Belgium.

ENTRIKIN, J.N (1991). The betweeness of place. London: Macmillan Education.

GEERTZ, C (1989). A interpretação das culturas. Rio de Janeiro: Guanabara Koogan.

HAESBAERT, Rogério (2002). Territórios alternativos. São Paulo: Contexto.

HARVEY, David (2003). A condição pós-moderna. São Paulo: Edições Loyola.

HEIDEGGER, M (1979). Construir, Morar, Habitar. In: CHOAY, Françoise. $O$ Urbanismo. São Paulo: Perspectiva.

HOLZER, Wherter (2000). Memórias de viajantes: paisagens e lugares de um novo mundo. Revista GEOgraphia, UFF. Niterói. Ano II. ${ }^{\circ} 3$.

HUDSON, A.C (1998). Placing trust, trusting place: on the social construction of offshore financial centres. Political Geography, Vol. 17, n.8, Nov., pp. 915-937.

INTERNATIONALE SITUACIONNISTE. No 3, 1959.

LEFEBVRE, Henri (1991). The production of space. Oxford/Cambridge: Blackwell.

MASSEY, Doreen (2002). Um sentido global do lugar. In: ARANTES, A (Org.) O Espaço da Diferença. Campinas, SP: Papirus. p.176-185.

(2004). Filosofia e política da espacialidade: Algumas considerações. Revista GEOgraphia, UFF. Niterói. Ano VI. nº 12.

(2009). Pelo espaço. Uma nova política da espacialidade. Rio de Janeiro: Bertrand Brasil. 
MELlO, J. B. F (1990). Geografia Humanística: a perspectiva da experiência vivida e uma crítica radical ao positivismo. Revista Brasileira de Geografia. 52 (4): 91-115.

MERLEAU-PONTY, Maurice (1994). Fenomenologia da percepção. São Paulo: Martins Fontes. 662 p.

MERRIFIELD, Andrew (1993). Place and space: a Lefebvrian reconciliation. Trans. Br. Inst. Geogr. N.S. 18: 516-531.

MOREIRA, R (2006). Para onde vai o pensamento geográfico? São Paulo: Contexto.

PRED, A. Place as historically contingent process: Structuration and the Time-Geography of becoming places. Annals of the Association of American Geographers. v. 74. Issue 2. 279-297.

RELPH, Edward (1976). Place and Placelessness. London: Pion.

RYBCZYNSKI, Witold (1995). Vida nas cidades: Expectativas urbanas no Novo Mundo. Rio de Janeiro: Record, 1995.

SANTOS, Milton (2000). Por uma outra globalização - do pensamento único à consciência universal. Rio de Janeiro: Record, 2000.

(2002). A Natureza do Espaço. São Paulo: Edusp. (2002). Da totalidade ao lugar. São Paulo: Edusp. (2007). Metamorfoses do Espaço Habitado. São Paulo: Edusp.

TUAN, Yi-Fu (1983). Espaço e Lugar: A perspectiva da experiência. São Paulo: Difel. 